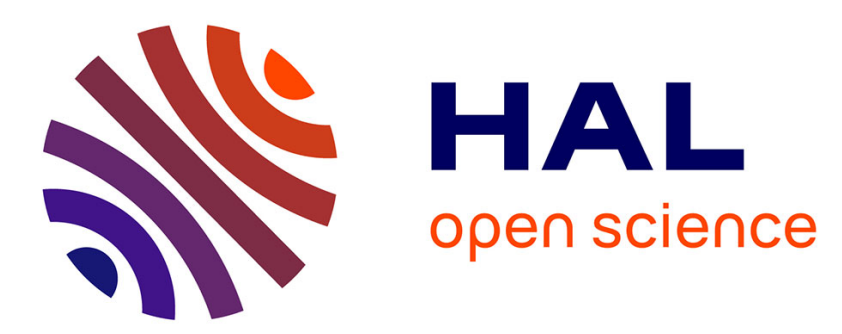

\title{
Correlation between pollen aperture pattern and callose deposition in late tetrad stage in three species producing atypical pollen grains
}

Béatrice Albert, Adrienne Ressayre, Sophie Nadot

\section{- To cite this version:}

Béatrice Albert, Adrienne Ressayre, Sophie Nadot. Correlation between pollen aperture pattern and callose deposition in late tetrad stage in three species producing atypical pollen grains. American Journal of Botany, 2011, 98 (2), pp.189-196. 10.3732/ajb.1000195 . hal-02648726

\section{HAL Id: hal-02648726 \\ https: / hal.inrae.fr/hal-02648726}

Submitted on 29 May 2020

HAL is a multi-disciplinary open access archive for the deposit and dissemination of scientific research documents, whether they are published or not. The documents may come from teaching and research institutions in France or abroad, or from public or private research centers.
L'archive ouverte pluridisciplinaire $\mathbf{H A L}$, est destinée au dépôt et à la diffusion de documents scientifiques de niveau recherche, publiés ou non, émanant des établissements d'enseignement et de recherche français ou étrangers, des laboratoires publics ou privés. 


\title{
CORRELATION BETWEEN POLLEN APERTURE PATTERN AND CALLOSE DEPOSITION IN LATE TETRAD STAGE IN THREE SPECIES PRODUCING ATYPICAL POLLEN GRAINS ${ }^{1}$
}

\author{
Béatrice AlberT ${ }^{2,3,5}$, Adrienne Ressayre ${ }^{2,3,4}$, ANd Sophie Nadot ${ }^{2,3}$ \\ ${ }^{2}$ Univ. Paris-Sud, Laboratoire Ecologie Systématique et Evolution, UMR8079, Orsay, F-91405; ${ }^{3}$ CNRS, Orsay, F-91405; and \\ ${ }^{4}$ INRA, Station de Génétique Végétale, Orsay, F-91405
}

- Premise of the study: Pollen grains of flowering plants display a fascinating diversity of forms, in spite of their minute size. The observed diversity is determined by the developmental mechanisms implicated in the establishment of pollen morphological features. Pollen grains are generally surrounded by an extremely resistant wall interrupted in places by apertures that play a key role in reproduction, being the places at which pollen tube growth is initiated. Aperture shape, number, and position are determined during microsporogenesis (male meiosis), the earliest step in pollen ontogeny. We investigate in detail the unfolding of microsporogenesis in three species that present uncommon aperture pattern (i.e., disulculate in Calycanthus floridus [Calycanthaceae, magnoliids], tetraporate in Hohenbergia stellata [Bromeliaceae, monocots], and monoporate in Typha latifolia [Typhaceae, monocots]).

- Methods: We performed a comparative analysis of microsporogenesis and aperture distribution within tetrads in these species with contrasting aperture arrangements. This was done using aniline blue coloration and UV light microscope observations.

- Keys results: We show that aperture localization and features of callose deposition on intersporal walls produced during cytokinesis coincide in all three species examined. Such a correlation suggests that patterns of callose deposition are strongly involved in determining aperture localization.

- Conclusion: In flowering plants, patterns of male meiosis and especially callose deposition following meiosis may be implicated in the diversity of pollen aperture patterns.

Key words: aperture pattern; callose; Calycanthus floridus; microsporogenesis; Hohenbergia stellata; intersporal wall formation; Typha latifolia.

The pollen grains of angiosperms display variation in many of their morphological features. One of these features is the aperture pattern, which is defined as the shape, number, and position of apertures on the surface of the pollen grain. The apertures play a major role in pollen-grain survival and reproductive success (Dajoz et al., 1991; Till-Bottraud et al., 1994, 1999, 2001). A wide range of variation in aperture pattern is observed throughout angiosperms (Erdtman, 1952). Variation occurs at any taxonomic level, even down to the intra-individual level. Nevertheless, large categories can be recognized within angiosperms according to the predominant aperture type. Basal angiosperms and monocots mainly produce monosulcate pollen grains (i.e., a single aperture located at the distal pole), whereas eudicots tend to produce tricolpate pollen grains (i.e., three apertures equally distributed along the equatorial region).

Wodehouse (1935) first proposed that meiotic cytokinesis is involved in aperture pattern ontogeny. Microspores are produced by meiosis. Before meiosis, microsporocytes produce a callose envelope within which meiosis takes place. Depending on the species, cytoplasmic divisions take place successively after each of the two nuclear divisions (successive cytokinesis) or simultaneously after the completion of both nuclear divisions

\footnotetext{
${ }^{1}$ Manuscript received 3 June 2010; revision accepted 9 December 2010.

The authors thank the Jardin Botanique de la Ville de Paris (France) and the Parc Botanique de Launay (Orsay, France) for their help with the plant material.

5 Author for correspondence (beatrice.albert@u-psud.fr)

doi:10.3732/ajb.1000195
}

(simultaneous cytokinesis). The intersporal walls that separate the microspores are composed of callose. Once meiosis is completed, microspores remain grouped in tetrads until outer and intersporal callose walls are digested by the enzyme callase. In most species, apertures become visible during the tetrad stage, and Wodehouse (1935) suggested that the spatial information determining aperture locations within the tetrad is provided by the last contact points persisting at the end of cytokinesis between the cytoplasms of the future microspores. He based this hypothesis on the observation of "frozen tetrads" of chicory, tetrads resulting from abortion during cytokinesis. In these tetrads, the microspores remain attached together by "tubes" that link the sites where aperture would have been formed if development had proceeded normally. Wodehouse's hypothesis served as a basis for the recent models developed to account for aperture ontogeny (Blackmore and Crane, 1988; Ressayre et al., 2002a). It applies especially well in eudicots, in which grouped apertures at the last contact points between microspores have been observed in a large set of species (Huynh, 1976). Ressayre et al. (2002a) have proposed a model that predicts these last contact points between microspores. This model is based on the interaction among three meiotic characters: the type of cytokinesis, the tetrad shape (which results from the relative orientation of the second meiotic axes), and the intersporal wall formation. Cytokinesis type (successive/simultaneous) and tetrad shape (tetragonal/rhomboidal/tetrahedral) determine the number and spatial arrangement of cleavage walls among nuclei. The mode of cleavage wall formation (centrifugal/centripetal) and the number and spatial distribution of these walls determine the areas where cytokinesis will be completed (Fig. 1). 
The model of Ressayre et al. (2002a) furthermore proposed to account for polar apertures in addition to grouped ones. Three studies based on the effect of disturbances of meiosis by drugs or centrifugation on the aperture pattern in wheat (Dover, 1972) and in Lilium (Sheldon and Dickinson, 1983, 1986), which have pollen grains with a single distal furrow, have shown that distal polar aperture formation is dependent on the position of meiotic poles. In addition, when distal apertures have the shape of a furrow, the extremities of the furrows point toward the areas where apertures would be located in the case of grouped apertures (Ressayre et al., 2002a). This latter observation suggests that determination of polar aperture pattern depends not only on the orientation of meiotic spindles but also on the location of areas where cytokinesis is completed, as with grouped aperture pattern.

The model of Ressayre et al. (2002a) indicates that the combination of variation in these few elements is sufficient to
A

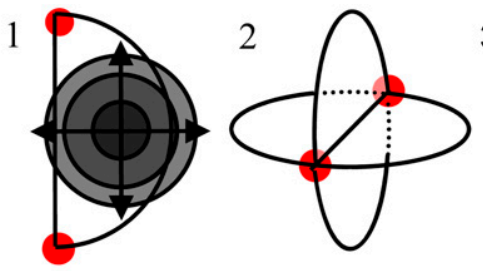

B
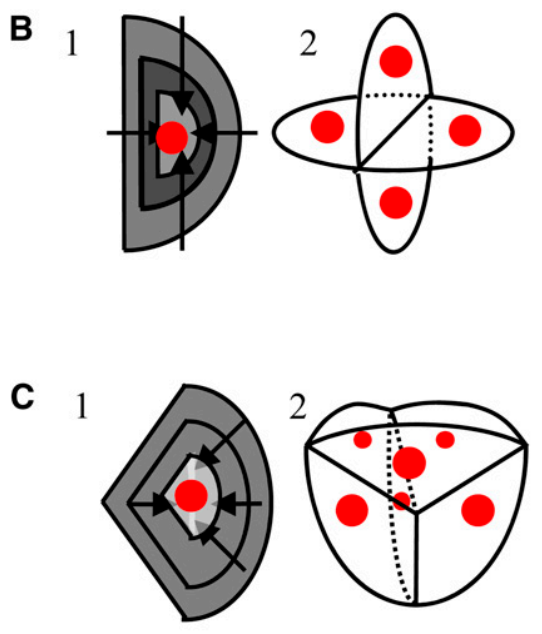

3

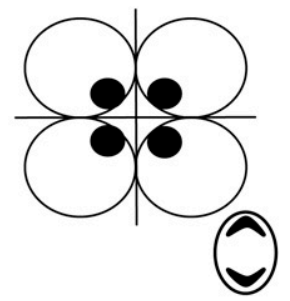

3

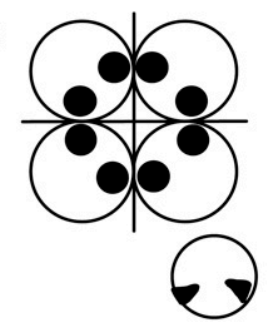

3

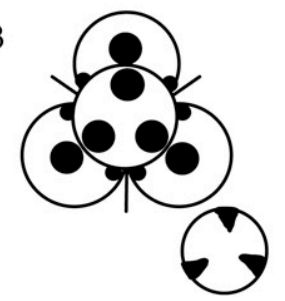

Fig. 1. Relationship among aperture distribution, tetrad shape, and cleavage wall formation. (1) Last point of callose deposition within each intersporal plane (red points). (2) Last points of callose wall deposition within tetrad (red points). (3) Aperture distribution within tetrad (black points), and pollen grain in a polar view on the right side. (A) Centrifugal callose wall deposition in a tetragonal tetrad. (A1) There are two last points of callose deposition within each plane. (A2) Tetragonal tetrad include four planes; there are two resulting points where callose is deposited last. (A3) Pollen grains present two apertures located at the distal pole of the tetrad. (B) Centripetal callose wall formation within tetragonal tetrad. (B1) There is one last point of callose deposition within each plane. (B2) Tetragonal tetrad includes four planes; there are four resulting points where callose is deposited last. (B3) Pollen grains present two apertures located at the equator in relation to the tetrad. (C) Centripetal callose wall formation within a tetrahedral tetrad. C1) There is one last point of callose deposition within each plane. (C2) Tetrahedral tetrad includes six planes; there are six resulting points where callose is deposited last. (C3) Pollen grains present three apertures located at the equator in relation to the tetrad. account for the commonly observed pollen aperture types. Here, to improve the model of Ressayre et al. (2002a), we explore the ontogeny of three uncommon aperture patterns that are not accounted for by the model. Typha latifolia L. (Typhaceae, monocots) produces monoporate pollen grains shed in tetrads. A large variation in tetrad shape is described in this species, and the pore of each microspore is not always located at the distal pole of the microspore, as is usually the case for monocots, but appears to vary with the position of the microspores within the tetrad (Wodehouse, 1935). Hohenbergia stellata Schult. \& Schult.f. (Bromeliaceae, monocots) produces four-porate pollen grains (Halbritter, 2000) of which the pore distribution within tetrad was undescribed before this work and cannot be predicted by the model of Ressayre et al. (2002a). Calycanthus glaucus L. (Calycanthaceae, magnoliids) produces pollen grains displaying two furrows located along the equator (disulculate pollen; Erdtman, 1952; Huynh, 1976; present study). In all three species our observations show that the process of callose deposition continues even after the completion of cytokinesis. In addition, the observation of aperture distribution within tetrads indicates that aperture position correlates with the position of these additional callose deposits. This strongly suggests that patterns of callose deposition are an important aspect of aperture ontogeny.

\section{MATERIALS AND METHODS}

Plant material-Typha latifolia L. and Calycanthus floridus L. were collected in the Parc Botanique de Launay (Orsay, France). Hohenbergia stellata Schult. \& Schult.f. was sampled from the Jardin Botanique de la Ville de Paris (Paris, France).

Microscopy-Fresh flower buds from the three species were collected at various developmental stages from multiple individuals. Several flower buds per individual and several stamens per bud were sampled and observed for each developmental stage. The anthers were dissected out, immediately squashed, and mounted in Aniline Blue to which $15 \%$ glycerol was added, following a modified protocol of Arens (1949). With this method, callose becomes fluorescent when UV illuminated (DAPI filter). Mature tetrads of $C$. floridus were stained with Congo red (Stainier et al., 1967), which emphasizes the contrast between apertural zones and the rest of the pollen wall. We recorded the progression of intersporal callose wall formation, the deposition of additional callose, the resulting tetrad shape, and the arrangement of apertures within tetrad in the three studied species.

\section{RESULTS}

Typha latifolia - Cytokinesis is successive and occurs through the formation of centrifugal cell plates (Figs. 2, 3). Most tetrads are tetragonal (Figs. 4, 6, 8, 10), although linear, Z-shaped, and T-shaped tetrads are also observed (Figs. 5, 7, 9, 11, 12). There is no additional callose laid onto the cell plates. At the tetrad stage, one plug of callose located toward the distal pole of each microspore can be observed in tetragonal (Fig. 6) and Z-shaped (Fig. 7) tetrads. The outer tetrad wall is still clearly visible (Fig. 6), showing that these callose knobs appear well before any dissolution of the callose wall. The knobs remain after the dissolution of the callose wall has begun (Fig. 8). For other tetrad shapes, one plug of callose per microspore is also observed, although not always located at the distal pole (Fig. 9). Pollen grains are shed in tetrad, and the comparison with pore distribution in pollen tetrads (Fig. 10-12) reveals that callose plugs are located in the areas where apertures are observed on mature pollen grains. 

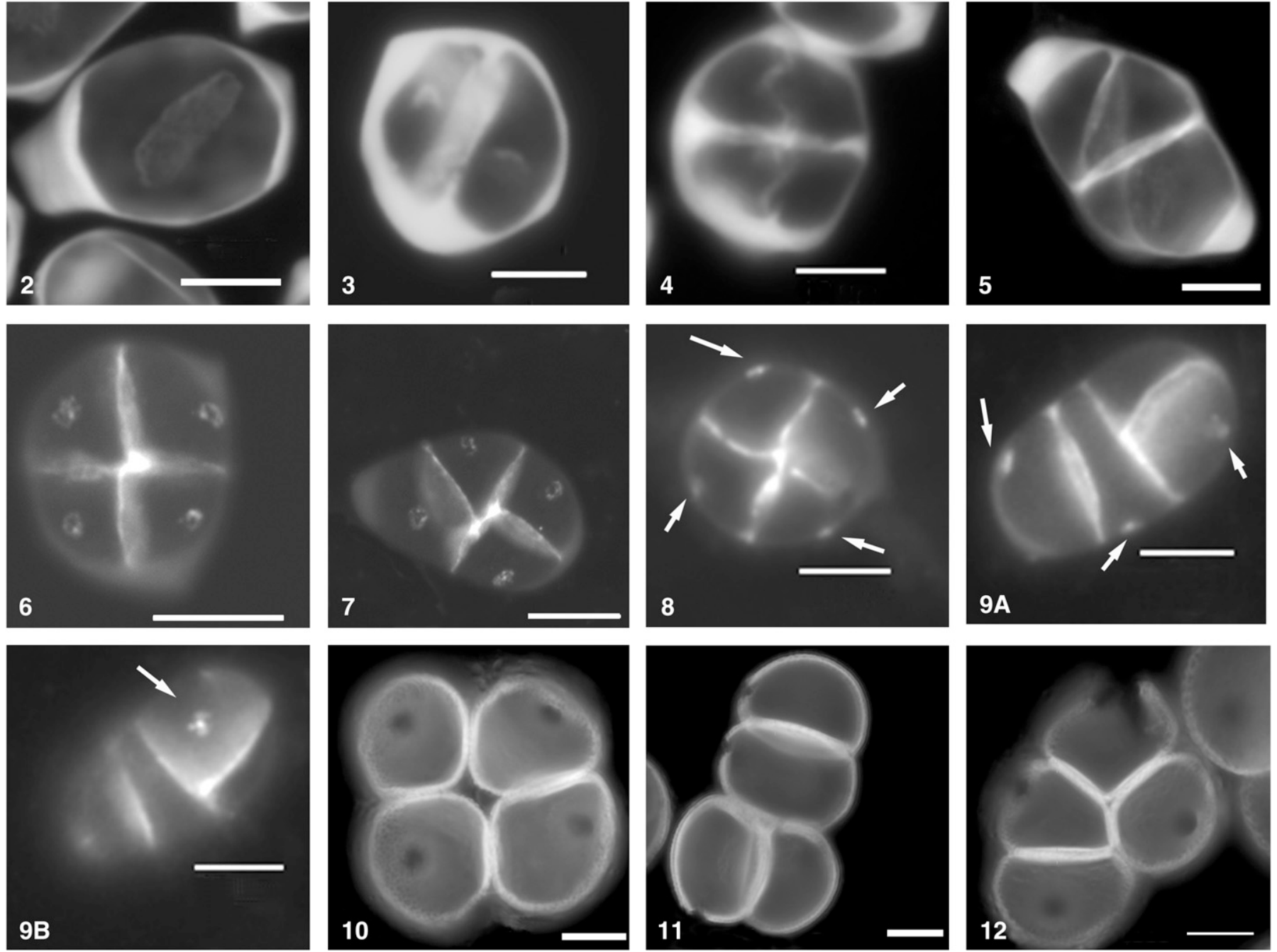

Figs. 2-12. Intersporal wall formation, tetrad shape, and aperture arrangement within tetrads, and tetrads of pollen grains in Typha latifolia. (Fig. 2) Centrifugal cell plate formation after the first meiotic division. (Fig. 3) Centrifugal cell plate formation after the second meiotic division. (Fig. 4) Tetragonal tetrad just after the completion of cell plate formation. (Fig. 5) Z-shape tetrad just after the completion of cell plate formation. (Fig. 6) Tetragonal tetrad enclosed within a callosic wall not degraded, presenting four plugs of callose. (Fig. 7) Z-shaped tetrad enclosed within a callosic wall not degraded, presenting four plugs of callose. (Fig. 8) Tetragonal tetrad with four plugs of callose located toward the distal pole of each microspore (arrows); callosic wall has started to be degraded. (Fig. 9 A-B) Lower and upper focus of a T-shaped tetrad with four plugs of callose (arrows). The pore of the central microspore is not polar. (Fig. 10) Tetragonal tetrad of four monoporate pollen grains. (Fig. 11) T-shaped tetrad of four monoporate pollen grains. (Fig. 12) Z-shaped tetrad of four monoporate pollen grains. (Figs. 2-12) Aniline blue staining. Scale bar represents $10 \mu \mathrm{m}$.

Hohenbergia stellata-Cytokinesis is successive and occurs through the formation of centrifugal cell plates (Figs. 13, 14). Only tetragonal tetrads were observed (Fig. 15-17). Intersporal wall formation is completed through a complex pattern of deposition of additional callose onto the cell plates (Fig. 16). These callose deposits form two opposite masses located at the intersections between the cell plates and the outer tetrad wall (cell plates divide each mass in four at both intersections), and four other masses wrapping the distal edge of each intersporal wall (cell plates divide each mass in two), toward the median part of the wall (Fig. 16). Therefore, callose deposits form four thickenings with respect to each microspore. Mature pollen grains present four pores arranged in two pairs along two orthogonal axes, a proximal axis and a subequatorial polar axis. At the end of the tetrad stage, the four pores of each future pollen grain are located precisely at the positions where the callose thickenings are formed (Figs. 17-19). As a result, the tetraporate pollen grain of $H$. stellata can be described as having two pores at both extremities of the proximal axis of the pollen, and two others located on an orthogonal axis in a subequatorial distal position (Fig. 19).

Calycanthus floridus-Cytokinesis is simultaneous and occurs through the formation of centripetal cell plates (Fig. 20). Asymmetric tetrahedral tetrads (i.e., multiplanar tetrads were observed; Figs. 21-24, 26, 27). The six cleavage planes are not of equal size, two of them being larger, the four others narrower, and leading to different angles among the cleavage planes within the tetrad (Fig. 22). Intersporal wall formation is completed through the deposition of additional callose on the cell plates (Figs. 22-24). The callose is first deposited toward the center of the tetrad on the four small cleavage walls. At a 

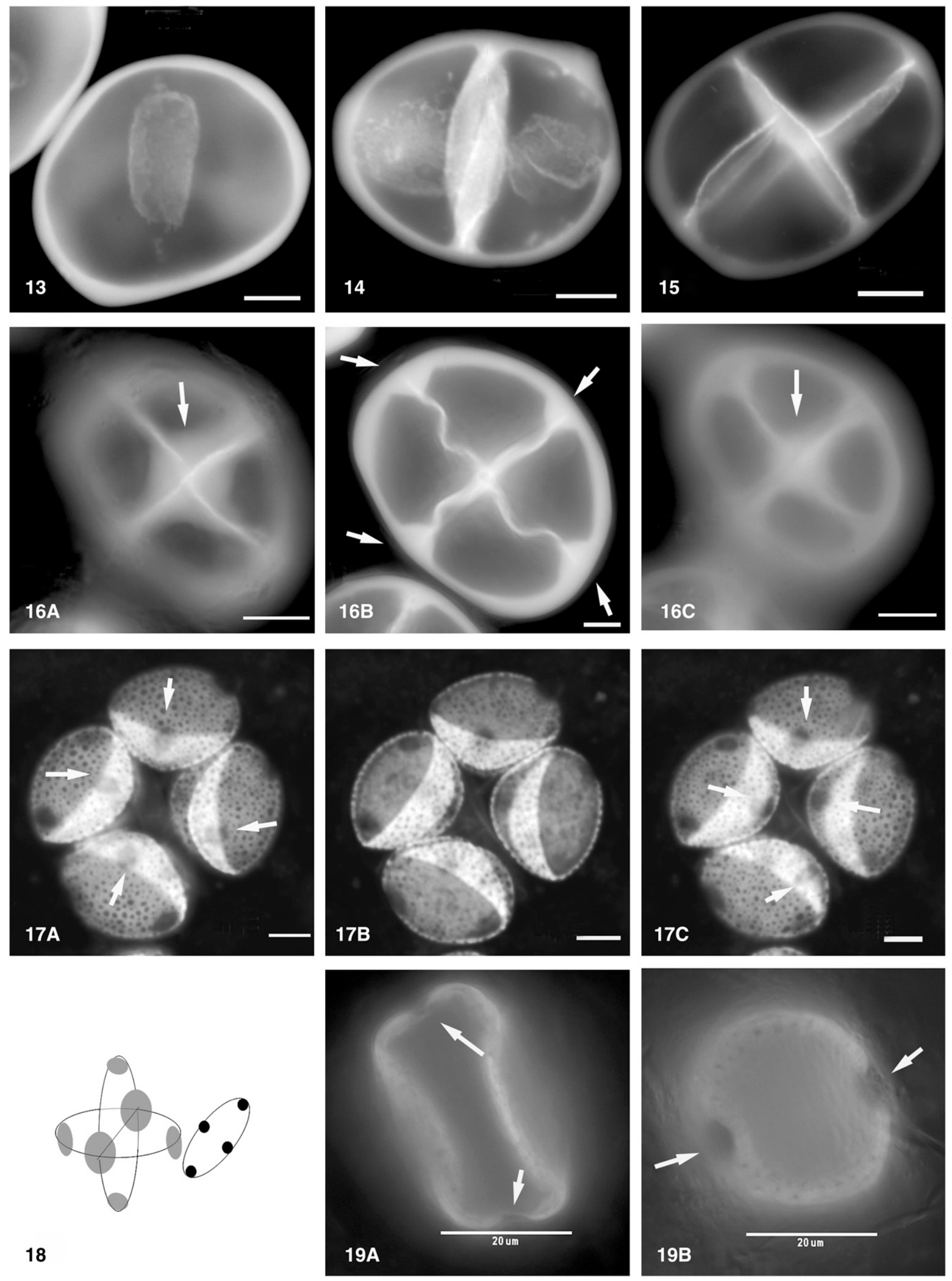
later stage, all cell plates are embedded in thick additional callose deposits. At this stage the microspores still have a round shape (Fig. 23). Just before the completion of callose deposition, microspores acquire a flat shape (Fig. 24), large masses of callose having accumulated on the small cleavage walls. Callose deposition can also be observed along the intersections of the large cleavage walls and the microsporocyte wall, as shown by the sharp outline of microspores in these regions. Mature pollen grains present two sulculi (Fig. 25). Microspores appear to form two pairs, each member of a pair displaying a joined furrow, the second furrow placed on the opposite side of the microspore and orthogonally to the furrows of the other pairs (Figs. 26, 27). The furrows appear to be located in the regions of intersections of the large cleavage walls and the microsporocyte wall, at places where callose is last deposited.

\section{DISCUSSION}

Although the three species differ strongly in their aperture patterns, callose deposition is a two-step process in all of them. Naked callosic cell plates are formed first, and wall formation is completed through the deposition of additional callose onto the walls in Hohenbergia stellata and Calycanthus floridus. In Typha latifolia, naked callosic cell plates are formed first, and plugs of callose are deposited later at specific places on the outer tetrad wall. Additional callose deposits are likely the driving factor in aperture pattern ontogeny, more or less disconnected from cell plate formation. Indeed, while cell plate formation occurs in only two different ways among the three species (centrifugally in both Typha latifolia and Hohenbergia stellata, centripetally in Calycanthus floridus), additional callose deposits are (1) totally different among the three species and (2) concentrated at specific places that coincide with the places where apertures are later located.

Our study demonstrates that Wodehouse's hypothesis of apertures being formed at last points of contact between the microspores can be dismissed in the case of the three studied species, in which we describe for the first time the complete unfolding of microsporogenesis and aperture distribution within tetrads. We show that both monocots (T. latifolia and H. stellata) present the typical microsporogenesis pathway of monocots, with successive cytokinesis, centrifugal cell plate formation, and tetragonal tetrad (Penet et al., 2005; Nadot et al., 2006; Sannier et al., 2007; Nadot et al., 2008). With such a formation of cell plates, the last contact points between microspores are expected to be located toward the outer tetrad wall at the intersections between the cleavage planes (Ressayre et al., 2002a), and the resulting aperture type should be monosulcate. We show that in $C$. floridus, cell plates are formed centripetally and future microspore cytoplasms are last connected in the center of the cleavage plans, which should result in tricolpate pollen
(Ressayre et al., 2002a). In none of the three species do the last cytoplasmic junctions correlate with aperture distribution.

We observed strong differences in additional callose deposits among the three species, and a correlation between last callose deposition and the position of the apertures within the tetrad in all three species. In Typha, this relationship is especially striking, because the position of the future aperture is marked by a distinct callose plug for each microspore. The callose plug is not the consequence of a differential dissolution of the tetrad callose wall, because the plugs are observed before any callose wall dissolution has taken place (Figs. 6, 7). In Hohenbergia, the patterns of callose deposition are complex. Four-way junctions of the intersporal walls on the one hand, and the middle of the distal edge of each intersporal wall on the other hand, exhibit distinct knobs of callose that are located where the pores are subsequently observed (Figs. 16-18). The same kind of correlation between additional deposits and aperture future sites is observed in Calycanthus, although the additional callose deposits are more difficult to describe. Nevertheless, the asymmetry in callose deposits can be linked with the positions of aperture within the tetrad. In fact, except for cell plate formation, microsporogenesis in Calycanthus presents strong similarities with the monocot species Asphodelus albus that produces monosulcate pollen grains (Huynh 1976). In Asphodelus, asymmetrical tetrahedral tetrads and additional callose deposits similar to those of Calycanthus are observed (Ressayre et al., 2005). Remarkably, one can interpret the very different aperture patterns of both species in a way that is consistent with the observed correlations in development. The extremities of the polar distal sulci of Asphodelus precisely meet where the center of the two sulcili of Calycanthus microspores are observed. Aperture distribution in both species can be linked to the last places of the tetrads where callose is deposited once the cell plates separate the microspores, which suggests again that callose deposition is involved in aperture pattern determination.

Our results corroborate those of earlier studies. First, Waterkeyn and Bienfait (1970) reported that knobs of callose corresponding to aperture location were found within hexagonal callosic meshes in Ipomoea purpurea. Later, Blackmore and Barnes (1987) showed that there is a link between differential tetrad callose wall deposition and primexine location in Tragopogon porrifolius. Recently, similar results have been described for six other species, namely Protea lepicarpodendron (Proteaceae) and Helleborus foetidus (Ranunculaceae; Ressayre et al., 2005), two eudicot species that produce, respectively, triporate and tricolpate pollen grains; and four monocot species-Pontederia cordata (Ressayre, 2001), Asphodelus albus, Phormium tenax (Ressayre et al., 2005), and Tillandsia leiboldiana (Albert et al., 2010) - that produce, respectively, diporate pollen grains with grouped apertures within tetrad, monosulcate pollen grains, trichotomosulcate pollen grains, and monosulcate pollen grains with a proximal sulcus. In this collection of species belonging

Figs. 13-19. Intersporal wall formation, tetrad shape, and aperture arrangement within tetrads and pollen grains in Hohenbergia stellata. (Fig. 13) Centrifugal cell plate formation after the first meiotic division. (Fig. 14) Centrifugal cell plate formation after the second meiotic division. (Fig. 15) Tetragonal tetrad just after the completion of cell plate formation. (Fig. 16) Lower (A), middle (B), and upper (C) focus on a tetragonal tetrad with additional callose deposits. On the lower and upper focus, thick deposits are observed at the intersection between the cell plates (arrow). On the middle focus (B, cross section of the tetrad), thick deposits are observed toward the edge of the cell plates (arrows). (Fig. 17) Lower (A), middle (B), and upper (C) focus on a mature tetragonal tetrad. The four pores of each microspore can be divided into two pairs in two levels, one pair proximal, the other subequatorial. The proximal pores are joined four by four (A, B, arrows), and the subequatorial pores are joined two-by-two. (Fig. 18) Diagram of additional callose (gray) within tetragonal tetrad, and pollen grain with apertures (black circles). (Fig. 19) Lower (A) and upper focus (B) on a pollen grain with four pores (arrows). (Figs. 13-17, 19) Aniline blue staining. Scale bar $=10 \mu \mathrm{m}$. 

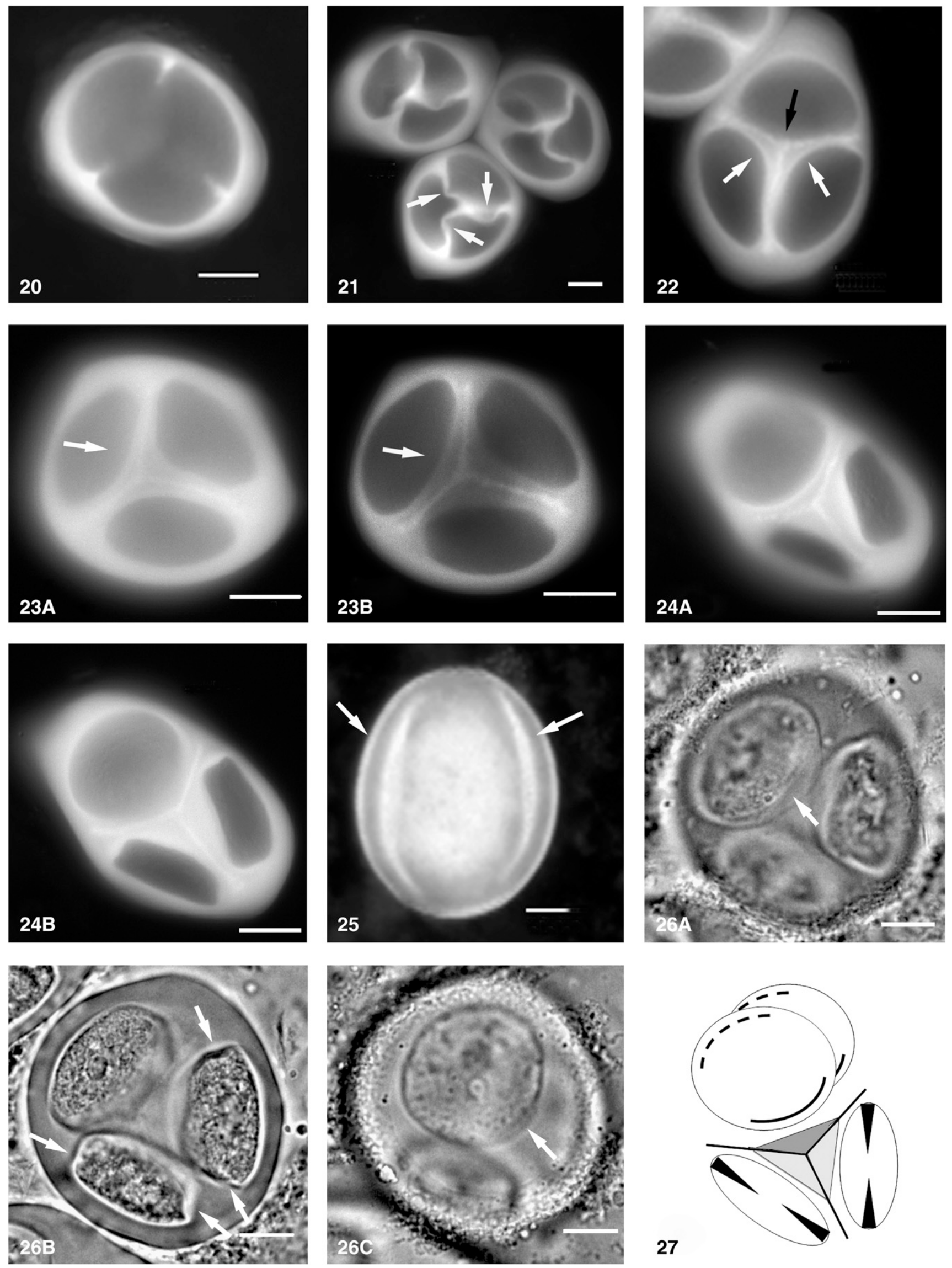
both to monocots and eudicots, microsporogenesis encompasses most of the developmental variation described in angiosperms (successive and simultaneous cytokinesis, centrifugal and centripetal cell plate formation, tetrad shape variation), and the last points where additional callose is deposited always correspond to the places where the apertures are located (Pontederia cordata, Protea lepicarpodendron, Helleborus foetidus, and Tillandsia leiboldiana) or to the places toward which the apertures are oriented (Asphodelus albus and Phormium tenax).

The functional validation of the correlation between callose deposition and aperture pattern could be explored using Arabidopsis cals 5 mutants. Callose deposition in the cals 5 mutants is nearly completely lacking in meiocytes, tetrads, microspores, and mature pollen, which suggests that the CALS5 gene is essential for callose synthesis in these tissues (Dong et al., 2005; Nishikawa et al., 2005). The cals 5 mutants described by Nishikawa et al. (2005), Dong et al. (2005), and Suzuki et al. (2008) present modification in exine patterning, thus demonstrating the implication of callose in the latter. Modification in aperture pattern was observed (but not studied in detail) in several cals5 mutants (Dong et al., 2005; Enns et al., 2005; Nishikawa et al., 2005), which suggests that callose deposition is involved in aperture pattern ontogeny.

In eudicots, cell plate formation and callose deposition onto the cell plates are generally synchronized (Wodehouse, 1935; Ressayre et al., 2002b; Blackmore et al., 2007), and the last points of contact between microspores correspond to the last points of callose deposition. This explains why the position of apertures was believed to be at the last points of contact among microspores. Our observations of species that produce uncommon aperture patterns suggest that the driving mechanism in aperture pattern determination is callose deposition rather than cytoplasmic contact. Therefore, no matter the way in which additional callose is deposited in relation to cell plate formation (synchronized or not), the aperture positions within the tetrad can be related to the point(s) where callose is deposited last. This holds true for species belonging to eudicots (Ressayre et al., 2005), monocots (Ressayre, 2001; Ressayre et al., 2005; Albert et al., 2010; present study), or basal angiosperms (present study). The wide diversity of aperture pattern observed in angiosperms therefore seems linked to the diversity observed in patterns of callose deposition. This correlation between callose deposition and aperture position seems to be a conserved phenomenon throughout land plants, given that it is also observed in Physcomitrella patens (Schuette et al., 2009).

\section{LITERATURE CITED}

Albert, B., A. Matamoro-Vidal, C. Raquin, and S. Nadot. 2010. Formation and function of a new pollen aperture pattern in angiosperms: The proximal sulcus of Tillandsia leiboldiana (Bromeliaceae). American Journal of Botany 97: 365-368.

ARENs, K. 1949. Prova de calose por meio da microscopia a luz fluorescente e aplicações do metodo. Lilloa 18: 71-75.

Blackmore, S., AND S. H. Barnes. 1987. Pollen wall morphogenesis in Tragopogon porrifolius L. (Compositae: lactuceae) and its taxonomic significance. Review of Palaeobotany and Palynology 52: 233-246.

Blackmore, S., and P. Crane. 1988. The systematic implications of pollen and spore ontogeny. In Humpries, C. J. (ed.), Ontogeny and Systematics, 83-115. Columbia University Press, New York, New York, USA.

Blackmore, S., A. H. Wortley, J. J. Skvarla, AND J. R. Rowley. 2007. Pollen wall development in flowering plants. New Phytologist 174: 483-498.

Dajoz, I., I. TILl-Bottraud, And P. Gouyon. 1991. Evolution of pollen morphology. Science 253: 66-68.

Dong, X., Z. Hong, M. Sivaramakrishnan, M. Mahfouz, and D. P. S. Verma. 2005. Callose synthase (CalS5) is required for exine formation during microgametogenesis and for pollen viability in Arabidopsis. Plant Journal 42: 315-328.

Dover, G. A. 1972. The organization and polarity of pollen mother cells of Triticum aestivum. Journal of Cell Science II: 699-711.

Enns, L. C., M. M. Kanaoka, K. U. Torit, L. Comai, K. Okada, and R. E. Cleland. 2005. Two callose synthases, GSL1 and GSL5, play an essential and redundant role in plant and pollen development and in fertility. Plant Molecular Biology 58: 333-349.

Erdtman, G. 1952. Pollen morphology and plant taxonomy: Angiosperms (an introduction to palynology). Almqvist and Wiksell, Stockholm, Sweden.

Halbritter, H. 2000. Hohenbergia stellata. In Buchner, R., and Weber, M. (eds.), PalDat—a palynological database: Descriptions, illustrations, identification, and information retrieval. Society for the Promotion of Palynological Research in Austria. Available oat http:// www.paldat.org/.

HuYNH, K. L. 1976. Arrangement of some monosulcate, disulcate, trisulcate, dicolpate and tricolpate pollen types in the tetrads, and some aspects of evolution in the angiosperms. In I. K. Ferguson and M. Muller (eds.), The evolutionary significance of the exine, 101-124. Academic Press, London, UK.

Nadot, S., A. Forchioni, L. Penet, J. Sannier, and A. Ressayre. 2006. Links between early pollen development and aperture pattern in monocots. Protoplasma 228: 55-64.

Nadot, S., C. A. Furness, J. Sannier, L. Penet, S. Triki-Teurtroy, B. Albert, And A. Ressayre. 2008. Phylogenetic comparative analysis of microsporogenesis in angiosperms with a focus on monocots. American Journal of Botany 95: 1426-1436.

$\leftarrow$

Figs. 20-27. Intersporal wall formation, tetrad shapes, and aperture arrangements within tetrads and pollen grains in Calycanthus floridus. (Fig. 20) Simultaneous cytokinesis with centripetal cell plate formation. (Fig. 21) Tetrahedral tetrad just after completion of cell plate formation; arrows indicate the last points of contact between the cytoplasm of the newly formed microspores. (Fig. 22) Asymmetric tetrahedral tetrad presenting additional callose deposits on cell plates. Note the asymmetry of callose deposition, correlated with the asymmetry of the tetrad: the upper angle presenting no additional callose deposit at this stage (black arrow) is larger than the lower two which present callose deposits (white arrows). (Fig. 23) Lower (a) and middle (b) focus on a tetrad during additional callose deposition, all cell plates are now embedded with callose. (Fig. 24) Lower (a) and middle (b) focus on mature tetrad. Microspores acquired a flat shape with sharp edges. (Fig. 25) Disulculate pollen grain (furrows indicated by arrows). (Fig. 26) Lower (a), middle (b), and upper (c) focus on an asymmetric tetrahedral tetrad during pollen wall maturation. This tetrad has been chosen because it is exactly in the same orientation as the one shown in Figure 23. The four disulculate microspores are arranged in two orthogonal pairs, each pairs having a furrow located at the intersection of the surrounding microspore mother cell wall and the large cleavage wall separating them. This furrow is joined with the one of the other microspore of the pair, the other one being observed on the opposite side of the microspores. The furrows of the other microspore pair are orthogonally arranged. Arrows indicate furrows. (Fig. 27) Schematic illustration of the asymmetric tetrahedral tetrad shown in Figure 26. The sulculi are drawn in full and dotted black lines (dotted lines correspond to not visible sulculi). Additional callose deposits in tetrahedral tetrad are also represented. The first callose deposits are drawn in light gray (as in Fig. 22), and the last callose deposit in dark gray (as in Fig. 23). (Figs. 20-25) Aniline blue staining. (Fig. 26) Congo red staining. Scale bar represents $10 \mu \mathrm{m}$. 
Nishikawa, S.-I., G. M. Zinkl, R. J. Swanson, D. Maruyama, and D. Preuss. 2005. Callose ( $\beta-1,3$ glucan) is essential for Arabidopsis pollen wall patterning, but not tube growth. BMC Plant Biology 5: 22.

Penet, L., S. Nadot, A. Ressayre, A. Forchioni, L. Dreyer, and P. H. Gouyon. 2005. Multiple developmental pathways leading to a single morph: monosulcate pollen (examples from the Asparagales). Annals of Botany 95: 331-343.

RESSAYRE, A. 2001. Equatorial aperture pattern in monocots: same definition rules as in eudicots? The example of two species of Pontederiaceae. International Journal of Plant Sciences 162: 1219-1224.

Ressayre, A., B. Godelle, C. Raquin, and P. H. Gouyon. 2002a. Aperture pattern ontogeny in angiosperms. Journal of Experimental Biology 294: 122-135.

Ressayre, A., C. Raquin, A. Mignot, B. Godelle, and P. H. Gouyon. 2002b. Correlated variation in microtubule distribution, callose deposition during male post-meiotic cytokinesis, and pollen aperture number across Nicotiana species (Solanaceae). American Journal of Botany 89: 393-400.

Ressayre, A., S. Triky-Teurtroy, A. Forchioni, L. Dreyer, and S. NADOT. 2005. Post-meiotic cytokinesis and pollen aperture pattern ontogeny: comparison of development in four species differing in aperture pattern. American Journal of Botany 92: 576-583.

Sannier, J., C. B. Asmussen-Lange, M. Harley, and S. Nadot. 2007. Evolution of microsporogenesis in palms (Arecaceae). International Journal of Plant Sciences 168: 877-888.

Schuette, S., A. J. Wood, M. Geisler, J. Geisler-Lee, R. Ligrone, and K. S. Renzaglia. 2009. Novel localization of callose in the spores of Physcomitrella patens and phylogenomics of the callose synthase gene family. Annals of Botany 103: 749-756.
SHELDON, J., AND H. DiCKInSON. 1983. Determination of patterning in the pollen wall of Lilium henryi. Journal of Cell Science 63: 191-208.

Sheldon, J., AND H. Dickinson. 1986. Pollen wall formation in Lilium: The effect of chaotropic agents, and the organization of the microtubular cytoskeleton during pattern development. Planta 168: 11-23.

Stainier, F., D. Huard, and F. Bronkers. 1967. Technique de coloration spécifique de l'exine des microspores jeunes encore groupées en tétrade. Pollen et Spores 9: 367-370.

Suzuki, T., K. Masaoka, M. Nishi, K. Nakamura, and S. Ishiguro. 2008. Identification of kaonashi Mutants Showing Abnormal Pollen Exine Structure in Arabidopsis thaliana. Plant \& Cell Physiology 49: $1465-1477$.

Till-Bottraud, I., P. H. Gouyon, D. L. Venable, and B. Godelle. 2001. The number of competitors providing pollen on a stigma strongly influences intraspecific variation in number of pollen apertures. Evolutionary Ecology Research 3: 231-253.

Till-Bottraud, I., D. L. Venable, I. Dajoz, and P. H. Gouyon. 1994. Selection on pollen morphology: A game theory model. American Naturalist 144: 395-411.

Till-Bottraud, I., M. Vincent, I. Dajoz, and A. Mignot. 1999. Pollen aperture heteromorphism. Variation in pollen-type proportions along altitudinal transects in Viola calcarata. Comptes Rendus Biologies 322: 579-589.

WATERKEyn, L., AND A. Bienfait. 1970. On a possible function of the callosic special wall in Ipomea purpurea (L.) Roth. Grana 10: 13-20.

Wodehouse, R. P. 1935. Pollen grains: Their structure, identification and significance, in science and medicine. Hafner, New York, New York, USA. 